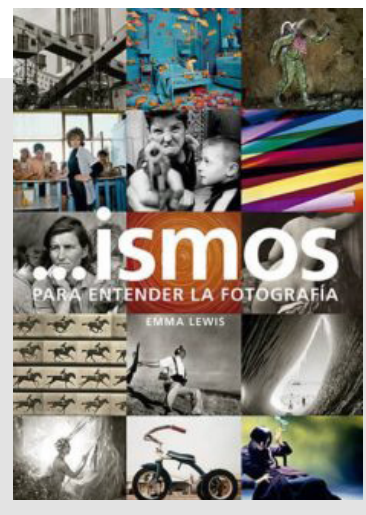

Ismos para entender la fotografía

Emma Lewis

Editorial Turner, Madrid 2017

\title{
¿Qué es y hacia dónde va la fotografía?
}

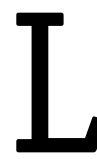

a revalorización de la fotografía en las últimas décadas ha traído consigo un aumento considerable de publicaciones sobre el medio. Entre ellas, merece la pena destacar este trabajo de Emma Lewis en el que se ofrece, desde la mirada de una curadora de arte contemporáneo, una recapitulación de las múltiples tendencias surgidas desde su invención en el siglo XIX.

Lewis sostiene que en la evolución de la fotografía han intervenido históricamente cuatro factores: la innovación tecnológica, sus corrientes históricas, su rol social y cultural, y su uso en el ámbito comercial (2017, p. 6). Tomando como base estos elementos, se presenta un catálogo de escuelas y movimientos divididos en etapas, advirtiendo previamente que cualquier propuesta de clasificación seguirá siendo objeto de controversia.

La primera de estas etapas nos lleva a su origen y desarrollo (1826-1920). A partir de la creación del daguerrotipo se explican los primeros usos de la fotografía, tanto en el mundo científico como en el ámbito social (los retratos de estudio, la fotografía de viajes o la fotografía temprana de conflictos bélicos), llegando hasta 
su empleo como documento social y de denuncia a principios del siglo XX gracias a fotógrafos como Hine o Riis.

El segundo periodo (1850-1940) aborda el salto a la modernidad, y la superación del debate decimonónico sobre el estatus de la fotografía como forma de arte, e incluye a una pléyade de autores como Cameron, Atget, Cartier-Bresson, Stieglitz, Steichen, Rodchenko, Man Ray, Moholy-Nagy, Sander, Modotti, Adams o Weston. Se describe el protagonismo del medio en vanguardias europeas como el Futurismo, el Constructivismo, el Surrealismo, la Bauhaus, o la Nueva Objetividad, y la aparición de colectivos esencialmente fotográficos como Photo-Secession o el Grupo f64.

La tercera etapa es la del desarrollo de la mirada humanista y social (19301979), iniciada con el realismo social que encarnan Ewans y Lange, al que sigue el esplendor del periodismo gráfico y del reportaje de guerra (Capa, Bourke-White, Arnold, Smith, o McCullin). En los años cincuenta nuevos talentos ofrecen originales visiones de la realidad social a través del objetivo de su cámara, como Arbus, Model o Klein. Steichen organizará la exposición The Family of Man (1955) y se publicará el influyente fotolibro The Americans (Frank, 1958).

Entre las décadas de 1970 y 1990 la fotografía adquiere un reconocimiento cultural gracias a su entrada en los museos y al surgimiento de instituciones especializadas y de manifestaciones populares como los festivales. Una etapa que Lewis define como la de la posmodernidad (1950-1999), en la que surgen movimientos como el Conceptualismo de Hilliard, la Nueva Topografía del matrimonio Becher, la fotografía en color de Eggleston, el documental artístico de Koudelka, el Diarismo de Goldin, los estudios de autorretrato e identidad de Mapplethorpe, o los Tableaux Vivants de Crewdson.

Llegamos así a la fotografía contemporánea, caracterizada por la llegada de la imagen digital y la aparición del concepto postfotografía. Etapa que trae nuevas corrientes como el Satirismo de Parr, el Neutralismo de Gursky, el Ecologismo de Salgado, el Activismo de Meiselas, o el Narrativismo de Ficción de Fontcuberta.

Encontramos finalmente un valioso listado de las principales colecciones y mu- 
seos internacionales en los cuales se pueden contemplar in situ los diferentes ismos referenciados en la obra.

Se trata en definitiva de una atractiva propuesta para comprender los postulados teóricos y estéticos de los diferentes ismos, y que sirve de complemento a la lectura de otros textos de referencia de autoras como Freund (1974), Sontag (1977) o Sougez (1981). Escrito desde una clara vocación pedagógica (el material es un excelente texto docente para la enseñanza académica de la fotografía), el interés de este libro radica en hacer accesible una historia tan fértil como compleja, planteando los diversos caminos por explorar en la fotografía de nuestro tiempo.

\section{Referencias}

Frank, R. (1958). The Americans (edición de 2008). Göttingen: Steidl.

Freund, G. (1974). La fotografia como documento social (edición de 2017). Barcelona: Gustavo Gili.

Lewis, E. (2017). Ismos para entender la fotografia. Madrid: Turner.

Sontag, S. (1977). Sobre la fotografía (edición de 2018). Barcelona: Penguin/ Random House.

Sougez, M.-L. (1981). Historia general de la fotografía (edición de 2007). Madrid: Cátedra.

\section{Adolfo Baltar-Moreno}

Profesor del programa de Comunicación Social Universidad Tecnológica de Bolivar https://orcid.org/0000-0002-1084-5045

Cartagena de Indias, Colombia

\section{(c) $\underset{\mathrm{EY}}{\mathrm{BY}}$}

Este obra está bajo una licencia de Creative Commons Reconocimiento 4.0 Internacional. 